\title{
A Newfangled Coordinated Ruthenium Phloretin Complex Reprogramming Breast Cancer Microenvironment Interceded by Modulation of PI3K/Akt/Mtor/VEGF Pathway and Modifying The Antioxidant Status Correlated With Intensified Apoptotic Events.
}

Chenyang He

Xi'an Jiaotong University Second Affiliated Hospital

Junli Wang

Youjiang Medical University for Nationalities

Tania Chakraborty

NSHM Knowledge Campus - Kolkata

Souvik Roy ( $\sim$ souvikroy35@gmail.com )

NSHM Knowledge Campus - Kolkata

Research

Keywords: Breast Cancer, DMBA, Metal complex, Apoptosis, Chemotherapy

Posted Date: August 5th, 2020

DOI: https://doi.org/10.21203/rs.3.rs-42460/v1

License: (c) (i) This work is licensed under a Creative Commons Attribution 4.0 International License. Read Full License 


\section{Abstract}

Background: Our recent investigation directed to synthesize and characterize a novel rutheniumphloretin complex accompanied by the study of antioxidant in addition to DNA binding capabilities, and to determine the chemotherapeutic activity against breast carcinoma in vitro and in vivo approach.

Methods: Ruthenium-phloretin complex was synthesized and characterized using various spectroscopic methods. The complex was further investigated to determine its efficacy in both MCF-7 and MDA-MB-231 human cancer cell lines and finally in an in vivo model of DMBA induced mammary carcinogenesis in rats

Results: Our studies confirm that the chelation of the metal and ligand was materialize by the $3-\mathrm{OH}$ and 9$\mathrm{OH}$ functional groups of the ligand and the complex is found crystalline and was capable of intercalating with CT-DNA. The complex was capable of reducing cellular propagation and initiate apoptotic events in MCF-7 and MDA-MB-231 breast carcinoma cell lines. Additionally, ruthenium-phloretin complex could modulate p53 intervene apoptosis in the breast carcinoma, initiated by the intrinsic apoptotic trail facilitated by the $\mathrm{Bcl} 2$ and $\mathrm{Bax}$ and at the same time down regulating the PI3K/Akt/mTOR pathway coupled with MMP9 regulated tumor invasive pathways.

Conclusions: Ruthenium-phloretin chemotherapy could interrupt, revoke or suspend the succession of breast carcinoma by altering intrinsic apoptosis along with the antiangiogenic pathway, hence fulfilling the role of a prospective candidate in cancer chemotherapeutics in the in the near future.

\section{Background}

Breast cancer is the most frequent of all carcinomas occurring in women, living in both developed and developing countries and estimated that worldwide over 6,26,679 women died in 2018 due to breast cancer (1). Breast cancer incidence in the Asian continent is still lower than that of Europe or America, but the participation of Asia to the global burden of breast cancer is increasing rapidly due to expressed economic growth and urbanization (2). Owing to their side effects and minimal effectiveness on tumors, current therapies have limitations leading to clinical resistance and therapy-related morbidity. Therefore, new medications are desperately needed to address emerging breast cancer cases including fewer side effects, effective tumor regression and decreased mortality.

The broad range of symmetries and coordinating numbers along with available redox states, thermodynamic/kinetic qualities as well as the variety of coordinating ligands, enables us to explore the unique characteristics of metal ions in the development of modern anti-cancer therapies (3;4). Cisplatin, is amongst the most widely used metal-based therapies for the treatment of malignant breast cancers, but these molecules typically have a variety of severe side effects owing to their absence of selectivity against normal and cancerous tissues (5). In addition to platinum-based chemotherapies, many 
endeavors have been dedicated to the development of ruthenium-based compounds, as these molecules recorded a smaller number of side effects owing to their alternative modes of action (6;7). Ruthenium complexes have been found to exhibit high cytotoxicity against platinum-resistant cancer cell lines in many cases, making them ideal targets for additional research $(8 ; 9)$. It should be noted that many complexes containing ruthenium such as RAPTA-C (10), NAMI-A, and KP1019 (11) have currently reached clinical trials for the management of various cancers.

Foods rich in fibers and a variety of colorful fruits and vegetables are considered part of a healthy diet in general, and prevent the development or progression of breast cancer and possess anti-carcinogenic, antimetastatic and immuno-modulatory activities, making them prospective contenders in cancer prevention and treatment (12). The role of flavonoids as antioxidants is already well-established and flavonoids interact directly with proteins, making them perfect small molecules in the regulation of enzymes, transcription factors and receptors (13). Amongst several polyphenols, phloretin [2', 4',6'-Trihydroxy-3-(4hydroxyphenyl)-propiophenone] is present in apple and in other plants, including Pieris japonica (14). Phloretin was capable of preventing the neoplastic progression of BALB/3T3 cells (15). Phloretin also has an inhibitory role on dextran sulfate sodium-induced ulcerative colitis in mice by altering nuclear factor- $K B$, toll-like receptor 4 and PPARy pathways (16). In addition, phloretin possesses diverse pharmaco-therapeutic effects on human malignancies, including the suppression of oral squamous cell carcinoma by modulating the glucose uptake (17), apoptosis in human gastric cancer by arresting the cell cycle of G2/M phase, suppression of cell invasion by diminution of JNK activity (18), attenuation of triple-negative breast cancer cell proliferation and migration (19) and promote apoptosis in human esophageal cancer (20). A very recent literature suggested that phloretin loaded chitosan nanoparticles augments the mitochondrial mediated intrinsic apoptosis in human oral cancer cells (21).

Substantial evidence states that development of cancer manifested unregulated proliferation along with impaired apoptosis $(22 ; 23)$ where $\mathrm{Bcl} 2$ and the tumor suppressor like p53 genes are thoroughly researched $(24 ; 25 ; 26)$. Bax and $\mathrm{Bcl}-2$ are the main pro-apoptotic regulators that can further enhance the PI3K / AKT related pathway and other cell survival and death associated trail (27). By regulating the matrix metalloproteinases (MMPs), natural agents can also influence invasion and metastasis of cancer cells. Among them, MMP-9 is of special concern as it has been reported that patients with enhanced MMP-9 expression will end up with weaker prognosis (28). Furthermore, the breast cancer progression involves mutations of p53, VEGF (modulated by angiogenic pathway), mTOR related signaling cascade, pro-apoptotic protein like Bax, and enhanced activation of Bcl2 like anti-apoptotic protein and proliferating cell nuclear antigen (PCNA) $(26 ; 29 ; 30 ; 31)$.

In addition, the current work utilizes molecular docking, a commonly employed bioinformatics tool, $(32 ; 33)$ especially applied herein to determine how the ruthenium-phloretin complex binds and interacts with the target proteins $\mathrm{Bcl}-2$. Autodoc is one such software consisting of a set of automated docking tools and designed to determine how molecules bind to a specific targeted protein with a pre-determined structure (34). 
To the best of our understanding, chemotherapeutic behavior in the model for breast cancer and the fundamental mechanistic approach of the ruthenium-phloretin complex has not yet been thoroughly studied. The present research aims at synthesizing, characterizing the complex of ruthenium-phloretin together with the investigation of antioxidant status, along with DNA binding properties and further examining the chemotherapeutic action against mammary cancer in both in vitro and in vivo experiments.

\section{Methods}

\section{Pharmacophore Analysis}

\section{Target protein selection}

The apoptotic signaling protein BCL2 (UID: P10415) sequence was recuperate from UniProt database (UID) and protein sequence used to predict sequence similarity and sequence templates by PSI-BLAST.

Ligand structure design and pharmacophore analysis

Chemical structures were designed the using ACD/ChemSketch software to add all chemical compositions and the final output was saved in MOL2 format.

\section{Molecular Docking}

AutoDock 4.6 software was used to predict the protein-ligand interaction using various parameters such as preparation of protein properties, addition of Gaussian charges, addition of hydrogen atoms with polar region of amino acids, preparation of ligand molecule with interaction of bonds with rotatable angles etc. The lowest energy conformations were regarded as the binding conformations between the ligands and the proteins.

Synthesis and Characterizations of ruthenium-phloretin complex

Detailed synthesis and characterization of the complex is described in the supplementary section.

Evaluation of antioxidant status of ruthenium phloretin complex by DPPH, FRAP, ABTS methods

\section{DPPH assay}

The complex ability to scavenge DPPH radicals was analysed using the method described by Dolatabadi (35). $\left(A_{c}\right)$ denotes blank and (As) denotes absorbance at every 5 minutes.

$(\operatorname{RSA} \%)=100\left(\mathrm{~A}_{C_{-}} \mathrm{A}_{S}\right) / \mathrm{A}_{C}$. 


\section{FRAP assay}

The test was performed using Benzie and Strain's protocol (36).

\section{ABTS assay}

ABTS radical scavenging activity of ruthenium phloretin complex was analysed using the procedure as described by Pennycooke and colleagues (37).

Radical Scavenging activity at $750 \mathrm{~nm}(\%)=1-\mathrm{A}_{\mathrm{f}} / \mathrm{A}_{0} \times 100$.

$A_{0}=$ Absorbance of uninhibited radical cation, $A_{f}=$ Absorbance measured 10-min after addition of the complex.

\section{Binding mode of DNA with ruthenium-phloretin complex}

Intercalation of CT-DNA with the compound was determined by using UV-Visible spectrophotometer (UV1800 Shimadzu), based on method reported by Dehghan (38). The binding constant was computed as:

$\mathrm{DNA} / \varepsilon_{\mathrm{a}}-\varepsilon_{\mathrm{f}}=\mathrm{DNA} / \varepsilon_{\mathrm{b}}-\varepsilon_{\mathrm{f}}+1 / \mathrm{K}_{\mathrm{b}}\left(\varepsilon_{\mathrm{b}}-\varepsilon_{\mathrm{f}}\right)$

DNA represents the number of base pairing of DNA, $\varepsilon_{a}$ represents the extinction coefficient $\left(A_{o b s} / R u\right)$ factor, $\varepsilon_{f}$ is extinction coefficient of free drug and $\varepsilon_{b}$ is extinction coefficient of bound drug derived from $\varepsilon_{\mathrm{f}}$ in the aqueous solution. $\varepsilon_{\mathrm{a}}$ represents the ratio of recorded absorbance to concentration of the complex by Beer's law.

In-vitro experimentation

\section{Cell culture}

The MCF-7and MDA-MB-231 breast cancer cell lines were purchased from NCCS, Pune and maintained under appropriate conditions.

\section{Cell viability assay}

The MCF-7 and MDA-MB-231 cells were plated for 24 hours in a $5 \% \mathrm{CO}_{2}$ humidified incubator and treated with various concentrations of ruthenium phloretin complex for 24 hours in 96 well plate. Upon treatment the medium was withdrawn and MTT solution was applied to each well and incubated for 3 hours. The optical density of solubilized crystals was estimated at $560 \mathrm{~nm}$. 
$\%$ viability $=100-\%$ of cytotoxicity

\section{DAPI staining apoptotic cells}

The cells were examined for nuclear blebbing and condensation of chromatin by dyeing them with DAPI using the process established by $\mathrm{Li}(39)$.

\section{Clonogenic assay}

Trypsinization of the cells were performed to produce a single cell suspension and were seeded in six well plate at a density of 500 cells / well. After 24 hours, culture was replaced with fresh media containing three different concentrations of complex with $2 \%$ FBS and incubated for two weeks then stained with $0.5 \%$ crystal violet in $25 \%(\mathrm{v} / \mathrm{v})$ methanol. The colonies were visually counted to contain $>50$ cells / colony.

Clonogenicity $=($ Cloning number/500x $) \times 100$.

\section{Cell cycle analysis and measurement of apoptotic assay by flow cytometry}

MCF-7 and MDA-MB-231 cells were suspended and their nuclear DNA was marked with propidium iodide (PI). The distribution of nuclear DNA in the cell cycle process was conducted on FACS (fluorescenceactivated shorter cell). A total of 10,000 events were acquired and flow-cytometric data processing was conducted using Modfit tools using the tool originated by Li (39).

\section{Detection of Caspase-3 protein expression by flow cytometry}

MCF-7 and MDA-MB-231 cells $\left(5 \times 10^{5}\right.$ cells/well) were cultured on six well plate and subsequently treated to three concentrations of ruthenium phloretin complex for 24 hours. Cell were incubated further by rabbit anti active caspase 3 polyclonal antibody (351-68655X, BD Pharmingen) for thirty minutes and analyzed by flow cytometry (BD Accuri C6 Plus flow cytometer).

\section{Detection of Akt, mTOR, p13K, VEGF, pro Caspase-3 and Active Caspase-3 protein expressions by western blot}

The cultured cells were treated with three separate doses of ruthenium-phloretin complex for 24 hours and cultured for $6 \mathrm{hrs}$. Cell lysates were processed and comparable protein quantities were analyzed by SDS-PAGE electrophoresis, accompanied by shifting to a PVDF (polyvinylidene difluoride) membrane. 
The membranes were incubated with the primary antibodies followed by the secondary antibody labeled with horseradish peroxidase for $1 \mathrm{hr}(40)$.

\section{In-vivo experimentation}

\section{Animal husbandry and maintenance}

Sprague Dawley rat (120-125 gm) and 28 days old virgin female Sprague-Dawley rats (80-100 grams) were acquired from IICB, Kolkata, India. The whole animal testing procedure was carried out in compliance with the endorsement of the Institutional Animal Ethics Committee \& the Government's Regulatory Body (Regd No. 1458/PO/a/11/CPCSEA).

\section{Toxicological investigation}

Details of the toxicological investigation of the complex is described in the supplementary section.

\section{In-vivo experiments}

\section{Experimental Protocol}

During acclimatization, the animals were grouped into seven groups and once the rats were 50 days old, DMBA was given as a single tail vein shot to animals of group II to VII at a dosage of $0.5 \mathrm{mg}$ per $100 \mathrm{~g}$ body weight in an oil emulsion. Group I normal untreated controls. Group Il carcinogen (DMBA) treated animals. Group III-V carcinogen induced animals accompanied by $50 \mathrm{mg} / \mathrm{kg}, 100 \mathrm{mg} / \mathrm{kg}$ and $200 \mathrm{mg} / \mathrm{kg}$ treatment with the Ru-phloretin complex. Group VI carcinogen induced animals with $100 \mathrm{mg} / \mathrm{kg}$ ruthenium treatment. Group VII carcinogen induced animals with $100 \mathrm{mg} / \mathrm{kg}$ phloretin treatment. After 16 weeks, the animals were sacrificed followed by midline incision from the pubis to the sub-maxillary

\section{Histopathology of mammary tissue}

Breast tissue was fixed in 10\% neutral buffered formalin, coated in paraffin, cut in $5 \mu \mathrm{m}$ thickness, and mounted on slides. For histopathological investigations the tissue segments were treated with hematoxylin and eosin (H\&E).

\section{Antioxidant status of mammary tissues}

Collected mammary tissues were compressed and homogenized (10\% w / v) in $0.1 \mathrm{M}$ phosphate buffer $(\mathrm{pH}$ 7.0). The homogenized mixture was centrifuged for 10 minutes to evaluate the antioxidant activity. 
The procedure of Jagatheesh was employed to obtain the activity of the supernatant (41). Catalase activity was carried out in the process described by Sinha and his colleagues (42). The activity of superoxide dismutase was conducted by the method of Awasthi (43). GPx activity was assessed using the Rotruck method (44).

\section{Immunohistochemical analysis of mammary tissue}

Paraffin embedded mammary tissue segments were deparaffinized accompanied by submersion in $\mathrm{H}_{2} \mathrm{O}_{2}$. The segments were covered with goat serum for 1 hour, followed by exposure to anti-mouse p53, Bcl2-, Bax- and MMP-9 antibodies (1:50 ratio) and kept overnight following labelling with the HRP-conjugated secondary antibody streptavidin biotin for $30 \mathrm{~min}$. DAB were used to stain the segments and counterstained with hematoxylin.

\section{Cell proliferating assay}

Tissue samples processed as above were covered with goat serum for 1 hour, followed by exposure to anti-mouse $\mathrm{Ki}-67$ antibody at $4{ }^{\circ} \mathrm{C}$ overnight. Tissues were stained with DAB and counter stained with hematoxylin (26).

\section{Apoptotic assay by TUNEL method}

Tissue samples processed as above were treated with proteinase $\mathrm{K}(20 \mu \mathrm{g} / \mathrm{ml}$ in PBS) for 15 minutes then treated with the terminal deoxynucleotidyl transferase (TdT) buffer accompanied by TdT and dUTP at $37^{\circ} \mathrm{C}$ for $90 \mathrm{~min}$. After washing the tissue were stained with $\mathrm{DAB}$ and counter stained with hematoxylin (26).

\section{Assessment of labelling and apoptotic index}

The labelling index (LI) was assessed as the percentage of Ki-67-positive nuclei /total number of cells counted. The apoptotic index (Al) was determined by calculating the percentage of TUNEL-positive cells / total number of cells.

\section{Statistical Analysis}

The results were defined as mean \pm standard error mean (SEM). Statistical evaluation was conducted by $\mathrm{t}$-test and one-way variance analysis (ANOVA) discrepancy was found to be statistically relevant when $\mathrm{P}$ $<0.05$ was used.

\section{Results}




\section{Pharmacophore Analysis}

The docking results shows that $\mathrm{Bcl}-2$ protein is strongly binds with ruthenium-phloretin within active site amino acids of both polar and electrostatic interactions within target amino acids of Tyr9, Asn182, Arg183, Thr187 and GIn190, with strong hydrogen bonding of $-9.52 \mathrm{kcal} / \mathrm{mol}$ of energy. (Table 1 and Supplementary Fig. 1B)

Table 1

Ligand with its binding energy values from docking studies

\begin{tabular}{|lllll|}
\hline Ligand & $\begin{array}{l}\text { No of } \mathbf{H}- \\
\text { bonds }\end{array}$ & $\begin{array}{l}\text { Binding } \\
\text { Energy }\end{array}$ & $\begin{array}{l}\text { Inhibitory } \\
\text { constant }\end{array}$ & Amino Acids \\
\hline $\begin{array}{l}\text { Ruthenium- } \\
\text { phloretin }\end{array}$ & 5 & -9.52 & 11.6 & $\begin{array}{l}\text { TYR 9, ASN 182, ARG 183, GLN 190 } \\
\text { and THR 187 }\end{array}$ \\
\hline
\end{tabular}

\section{In vitro antioxidant activity of ruthenium phloretin complex}

Ruthenium phloretin complex scavenges DPPH, FRAP and ABTS radicals

It was observed that by varying the concentrations of the complex, the absorption of activated ABTS at $734 \mathrm{~nm}$ dropped significantly (Fig. 1A). The complex was able to scavenge free radical more efficiently in the presence of ABTS as compared to free phloretin which could be attributed with the hydroxyl functional group and their capacity to contribute hydrogen atoms.

Figure 1(B) illustrated the scavenging of radicals by phloretin and ruthenium-phloretin complex, where the plot suggested that phloretin scavenged free radical to about $43 \%$ while the complex scavenged to about $79 \%$.

Declination in the absorbance of Fe + 3-TPTZ was observed in the presence of phloretin and rutheniumphloretin complex at $593 \mathrm{~nm}$. Figure 1(C) reaffirms that the complex possesses a greater antioxidant power than free phloretin.

Ruthenium-phloretin complex binds with CT-DNA

Upon addition of increasing amounts of the complex to CT-DNA, a decrease in the absorption intensity (hypochromism) of absorption peak is observed (Fig. 1D). After increasing the concentration of complex to the DNA, the intensity changes can be identified within the intra ligand transition band at $383 \mathrm{~nm}$. These spectral characteristics reveal that complex interacted with DNA via stacking interaction between the chromophore of the ligand through intercalative mode and the base pairs of DNAs.

\section{In vitro Assessment}

Ruthenium phloretin complex instigate the suppression of cell viability of MCF-7 and MDA-MB-231 cells 
The cell viability assessment designated that ruthenium-phloretin complex displayed a dose-dependent inhibitory effect on MCF-7 and MDA-MB-231 human breast cancer cells (Fig. 2A \& B). The viability of the MCF-7 cells following treatment was found to decrease to $68.84 \%, 57.03 \%$, and $33.43 \%$ at concentrations of 30,60 , and $120 \mu \mathrm{M}$ respectively. Similar results were noted in MDA-MB-231 cells where viability of the cell was found to decrease to $57.19 \%, 51.64 \%$, and $43.33 \%$ at concentrations 10,30 , and $60 \mu \mathrm{M}$ after 24 hours.

Ruthenium-phloretin complex causes chromatin condensation within MCF-7 and MDA-MB-231 cells.

Figure $2 C \& D$ shows that the complex induces nuclear condensation in a dose dependent manner in both cell lines. It was observed that the treatment with $120 \mu \mathrm{M}$ of complex in MCF-7 cells and $60 \mu \mathrm{M}$ of the complex in MDA-MB-231 cells exhibited the maximum condensation of chromatin, after 24 hours and signifies the highest expanse of apoptosis.

Ruthenium phloretin complex induces colony inhibition capability of MCF-7 and MDA-MB-231 cells

Ruthenium-phloretin complex successfully induces colony inhibition capability of MCF-7 and MDA-MB231 cells (Fig. 2E) The complex was significantly more effective in inhibiting both colony number (Fig. 2F\&G) and size (Fig. 2H\&l) of MCF-7 and MDA-MB-231 cells compared with untreated control cells. The plate efficiency (PE) for complex in both MCF-7 and MDA-MB-231 cells (Fig. 2J\&K) show significantly reduced PE at highest concentrations of complex in both MCF-7 and MDA-MB-231.

Effect of ruthenium-phloretin complex in cell cycle analysis and measurement of apoptotic assay by flow cytometry

Figure 3A \& D exhibited the allotment of MCF-7 and MDA-MB-231cells undergoing apoptosis following treatment with various concentration of the complex after 24 hours. Figure $3 \mathrm{~B}$ shows that the percentages of apoptotic cell are $16,39.07$ and $44.7 \%$ following treatment with 30,60 , and $120 \mu \mathrm{M}$ of the complex in MCF-7 cells and Fig. 3E represents 17.9, 42.25 and 46.9\% of MDA-MB-231 cells undergoing apoptosis following treatment with 10,30 and $60 \mu \mathrm{M}$ of the complex in MDA-MB-231. Moreover, a dose dependent increment in early apoptotic cell population was also observed in the cells after 24 hours of treatment with the complex (Fig. 3C \& F).

The number of sub diploid cells is represented by the apoptotic cells in the cell cycle histogram (Fig. 3G \& H). The MCF-7 treated with $30 \mu \mathrm{M}, 60 \mu \mathrm{M}$ and $120 \mu \mathrm{M}$ of the complex denoted $65.71 \%, 61.18 \%$ and $52.97 \%$ cells in the G0/G1 phase. Similar results were noted in MDA-MB-231 cells, where treatment with $10 \mu \mathrm{M}, 30 \mu \mathrm{M}$ and $60 \mu \mathrm{M}$ of the complex showed $63.77 \%, 55.66 \%$ and $41.94 \%$ cells in the $\mathrm{G} 0 / \mathrm{G} 1$ phase. Simultaneously, an increase of cells in the S-phase was noted after complex treatment in a dose dependent manner (Fig. 3I\&J) in both cell lines.

Effect of ruthenium-phloretin complex on Caspase 3 expression in MCF and MDA-MB-231 cells 
Figure $3 \mathrm{~K} \& \mathrm{~L}$ represented the flow cytometric analysis of caspase 3 activity of ruthenium phloretin complex on MCF-7 and MDA-MB-231cells at different concentration after 24 hours of complex treatment. Following drug treatment, the number of caspase 3 designated apoptotic cells in M2 quadrant is significantly higher than the living cells present in M1 quadrant while untreated cells showing significantly much number of living cells in quadrant M1 as compared to the caspase 3 designated apoptotic cells in M2.

Effect of ruthenium-phloretin complex in expression of PI3K, Akt, mTOR, EGFR, VEGF, and cleaved caspase 3 in MCF 7 and MDA-MB-231 cells.

Figure 3M, shows a dose-dependent down-regulation of PI3K, Akt, mTOR, EGFR and VEGF following 24 hours of treatment with ruthenium-phloretin complex in both MCF 7 and MDA-MB-231 cells. A notable up-regulation of cleaved caspase 3 was however observed in both MCF 7 and MDA-MB-231 cells following 24 hours of treatment with ruthenium-phloretin complex.

In vivo carcinogenesis study

Histological analysis

Figure 4A the normal control showed preserved normal alveoli (a), alveolar septa (as), terminal duct lobular units (td), acinus (ac) and serous gland (sg) of mammary tissue. Mammary tissue from DMBAtreated group showed atrophy of glands with periductal, stromal fibrosis and fatty tissue (psf), atrophy of glands with surrounding fatty tissue (ag), atrophy of serous glands (asg) surrounding stromal fibrosis, hyperplasia of serous and mucinous glands(ah) (Fig. 4B). 50 and $100 \mathrm{mg} / \mathrm{kg}$ complex treated groups showed slight hyperplasia of serous and mucinous glands (Fig. 4C\&D), whereas in the highest dose group showed normal histological profile, there was no sign of hyperplasia or cellular proliferation in mammary tissue and showed normal architecture of the cells surrounding the ducts (Fig. 4E). Phloretintreated group showed normal histological profile of rat mammary tissue (Fig. 4G) while ruthenium-treated DMBA group denoted atrophy of glands with surrounding fatty tissue (ag) and atrophy of serous glands (asg) (Fig. 4F).

\section{Antioxidant activity}

The homogenized mammary tissue of the DMBA-treated rats was found with a decline in SOD, CAT and diminished glutathione levels. The animals treated with $200 \mathrm{mg} / \mathrm{kg}$ of the complex showed a prominent increase in the levels of SOD, CAT and glutathione in the homogenized mammary tissues as opposed to carcinogen control and other groups (Fig. 4H).

\section{Immunohistochemical analysis}


The presence of cellular biomarkers were assessed by the immunohistochemical staining techniques (Fig. 5) (Table 2). It was observed that DMBA administration increased the levels of Bcl-2 [Figure 5 (ii) B] and MMP-9 [Figure 5 (iv) B] in a significant way whereas downregulating the expressions of Bax[Figure 5 (iii) B], p53 [Figure 5 (i) B] levels compared to the normal control group [Figure 5 (i), (ii), (iii) \& (iv) A] (p< 0.05). Ruthenium-phloretin therapy significantly increased the expressions of Bax [Figure 5 (iii) C, D \& E] and p53 [Figure 5 (i) C, D \& E] however a down regulation of Bcl-2 [Figure 5 (ii) C, D \& E] and MMP-9 [Figure 5 (iv) C, D \& E] were noted following ruthenium-phloretin therapy.

Table 2

Effect of ruthenium (Ru), phloretin (phl) and ruthenium phloretin complex (Ru-phl) on the expression of Bax, Bcl2, p53 and MMP9 in colon tissues.

\begin{tabular}{|c|c|c|c|c|}
\hline Groups & Bax $\S$ & $\mathrm{Bcl} 2^{\S}$ & p53§ & MMP9§ \\
\hline Control & $7.2 \pm 0.8$ & $7.9 \pm 0.1$ & $8.2 \pm 0.9$ & $8.6 \pm 0.4$ \\
\hline DMBA & $4.3 \pm 0.4$ & $15.4 \pm 1.8$ & $3.9 \pm 0.4$ & $19.4 \pm 0.9$ \\
\hline Ru-phl 50 mg/kg & $5.7 \pm 0.1^{\star \star}$ & $12.4 \pm 0.1^{\star \star}$ & $6.5 \pm 0.8$ & $15.2 \pm 0.5$ \\
\hline Ru-phl 100 mg/kg & $9.1 \pm 0.6^{*}$ & $9.6 \pm 0.2^{\star \star}$ & $9.5 \pm 0.1^{\star \star}$ & $12.2 \pm 0.5^{\star \star}$ \\
\hline Ru-phl 200 mg/kg & $11.7 \pm 1.8^{*}$ & $7.3 \pm 0.5^{*}$ & $14.4 \pm 0.6^{*}$ & $10.3 \pm 0.1^{*}$ \\
\hline \multicolumn{5}{|c|}{$\begin{array}{l}\$ \text { Each score represents the results of } 6 \text { slides per rat and } 6 \text { rats per group, mean } \pm \text { S.E. }(n=6) \text {. Each } \\
\text { field were selected randomly for evaluation of percentage of immune-positive cells. }\end{array}$} \\
\hline \multicolumn{5}{|c|}{ * Significant difference between treated and carcinogen control $(p<0.01)$. } \\
\hline ** Significe & {$[C$} & I & $<0.05)$. & \\
\hline
\end{tabular}

Suppression of Ki-67 by Ruthenium-phloretin complex

The efficacy of the ruthenium-phloretin compound in the proliferation of mammary tissues is designate in Fig. 6 (i) (Table 3). A significant rise in the Ki-67-LI values was observed in carcinogen control animals (Fig. 6 (i) B) in comparison to the normal control group (Fig. 6 (i) A), however a considerable reduction in the $\mathrm{Ki}-67-\mathrm{LI}$ index could be found in the maximum dose of ruthenium-phloretin complex treated animals $(p<0.01)$ (Fig. 6 (i) C, D \& E) in comparison to the carcinogen treated animals. 
Table 3

Cell proliferation and apoptosis in colon

\begin{tabular}{|c|c|c|c|}
\hline Groups & Ki-67-LI§ & $\mathrm{Al}(\%)^{\S}$ & $R=\mathrm{Ki}-67-\mathrm{LI} / \mathrm{Al}$ \\
\hline Normal control & $22.08 \pm 0.4$ & $0.17 \pm 0.02$ & $134.12 \pm 0.2$ \\
\hline DMBA & $36.2 \pm 1.3$ & $0.08 \pm 0.02$ & $452.05 \pm 0.5$ \\
\hline Ru- phl 50 mg/kg & $27.8 \pm 0.2$ & $0.07 \pm 0.05$ & $397.14 \pm 0.1$ \\
\hline Ru-phl 100 mg/kg & $21.8 \pm 0.1^{\star \star}$ & $0.11 \pm 0.02^{\# \#}$ & $198.18 \pm 0.2^{\$ \$}$ \\
\hline Ru-phl 200 mg/kg & $17.9 \pm 0.6^{*}$ & $0.12 \pm 0.03^{\#}$ & $149.16 \pm 0.9^{\$}$ \\
\hline \multicolumn{4}{|c|}{$\begin{array}{l}\mathrm{LI}=\text { Labelling index, } \mathrm{Ki}-67-\mathrm{LI}=\text { percentage of PCNA labelled cells/total number of cells counted, } \mathrm{Al}= \\
\text { Apoptotic index. } \mathrm{R}=\mathrm{PCNA}-\mathrm{LI} / \mathrm{Al} \text {. Al was calculated as the percentage of } \mathrm{TUNEL} \text { positive cells/total } \\
\text { number of cells counted. Values represents mean } \pm \mathrm{S} . \mathrm{E} \text {. }\end{array}$} \\
\hline \multicolumn{4}{|c|}{$\S$ Total number of six slides were evaluated per rat. Each field consisted of approximately 500 cells. } \\
\hline \multicolumn{4}{|c|}{$\begin{array}{l}\text { * Significant difference between Ki-67-LI of Ru- phl } 200 \text { mg/kg vs carcinogen control animals ( } p< \\
0.01 \text { ). }\end{array}$} \\
\hline \multicolumn{4}{|c|}{$\begin{array}{l}\text { ** Significant difference between Ki-67-LI of Ru } 100 \mathrm{mg} / \mathrm{kg} \text {, Ru- phl } 100 \mathrm{mg} / \mathrm{kg} \text { vs carcinogen control } \\
\text { animals }(\mathrm{p}<0.05) \text {. }\end{array}$} \\
\hline \multicolumn{4}{|c|}{ \# Significant difference between Al of Ru- phl 200 mg/kg vs carcinogen control $(p<0.01)$. } \\
\hline \multicolumn{4}{|c|}{$\begin{array}{l}\text { \#\# Significant difference between Al of Ru } 100 \mathrm{mg} / \mathrm{kg} \text {, Ru- phl } 100 \mathrm{mg} / \mathrm{kg} \text { vs carcinogen control } \\
\text { animals }(p<0.05) .\end{array}$} \\
\hline \multicolumn{4}{|c|}{ \$Significant difference between R of Ru- phl 200 mg/kg vs carcinogen control animals $(p<0.01)$. } \\
\hline
\end{tabular}

Ruthenium-phloretin complex promotes apoptosis

TUNNEL assay was carried out to visualize the result of ruthenium-phloretin treatment on apoptosis in breast cancer [Figure 6 (ii)]. The TUNEL positive cells undergoing apoptosis were very few in case of the carcinogen control group [Figure 6 (ii) B] in comparison to the normal control group [Figure 6 (ii) A]. The TUNEL positive cells of complex treated animals increased significantly [Figure 6 (ii) C, D \& E] when compared to the carcinogen control. Al defines the apoptotic index and is documented in Table 3. Animals receiving $200 \mathrm{mg} / \mathrm{kg}$ of the compound, denoted a substantial increase in apoptosis when contrasted to the carcinogen control group. The value $\mathrm{R}$ reflects the ratio of cell proliferation to apoptosis.

\section{Discussion}


Recent clinical trials in phase II have shown that the anticancer effects of phytochemicals or whole plant foods $(45 ; 46 ; 47)$ are manifested by low toxicity and can deliver a pragmatic therapeutic solution for cancer victims or high-risk individuals (48). In addition, flavonoids interact with transition metals creating complexes which shows greater oxidation potential with anticarcinogenic activity and has attracted increasing attention in recent years (49). In the past decades, ruthenium therapeutics have been used successfully in clinical research exhibited their profound anticancer activities (50). The concept of ruthenium-based cancer therapy is driven by the possibilities that several ruthenium compounds ideally accumulate in tumor tissue and provides additional coordination sites compared to platinum (II), and a number of ruthenium complexes exhibit redox activity under physiological conditions (51). Our current study encompasses the synthesis of a novel ruthenium-phloretin complex and evaluating its anticarcinogenic property against breast cancer in vivo and in vitro. Studies reveal that approximately $75 \%$ of primary breast cancer expresses elevated levels of Bcl-2 and considered to be involved a crucial role in the regulation of apoptotic events and cellular proliferation in breast cancer cells (52), thus it may be a promising candidate for anticancer therapy. Several small molecular inhibitors of Bcl-2, including ABT-737 and ABT-199, have been investigated extensively and offer potential as a prospective drug target $(53 ; 54)$. Prompted by this evidence and systemically address this issue, we took advantage of molecular docking studies to investigate the mode of interaction and to explore the binding mechanism of the novel complex against a target protein $\mathrm{Bcl}-2$. Our results denoted that the free binding energy for the complex was small thus favoring the binding orientation of compounds in the $\mathrm{Bcl}-2$ binding pocket surrounding the active site, which resulted in inhibition of enzyme activity. The complex was observed as an inhibitory candidate of Bcl-2, which may be considered as a potential ligand for treatment of breast cancer. Moreover, our study included synthesis and characterization of the complex. Result confirmed that the chelation materializes by the $3-\mathrm{OH}$ and $9-\mathrm{OH}$ functional groups of the ligand and the complex is found crystalline. The study of antioxidant activity revealed that the property of free radical scavenging of phloretin is considerably intensified on subsequent complexation with metal. Therefore, ruthenium facilitates to modify the oxidative capacity of phloretin following complexation by increasing the shifting of electrons from phloretin and hence escalating its redox potential. The reaction of the complex through CT-DNA ensued in a decline in spectrum of absorption of uncombined DNA, evidence of the phloretin complex intercalated with CT-DNA.

MTT assay revealed that ruthenium phloretin complex is capable of reducing cellular propagation and initiate apoptosis. An understanding into the mechanistic approach of the apoptotic induction by the complex was obtained by flow cytometry studies applying Annexin-V and PI staining. Additional, results showed that a greater proportion of early apoptotic events is marked by ruthenium phloretin on both MCF-7 and MDA-MB-231 cancer cells by detaining the cells in G0/G1 stage (Fig. 3I \& J) that consequently leads to cellular death.

A cell signaling cascade concerned with regulation of growth, proliferation, survival, motility, metabolism and immune response is the PI3K/Akt/mTOR pathway $(55 ; 56)$. The mammalian target of rapamycin (mTOR) is actively involved in tumor progression by triggering the PI3K/ Akt signaling trails (57). Variations to this pathway are observed in virtually all human tumors, along with breast cancer (58). 
Misregulation of this pathway is associated with unregulated proliferation, genomic instability and metabolic reprogramming in tumor cells $(59 ; 60)$. Additionally, activation of the PI3K / Akt / mTOR pathway is among the leading causes of resistance to current cancer chemotherapy (61) and the contribution of this pathway as a prospective therapeutic strategy and the prognostic and diagnostic value in breast cancer patients $(62 ; 63)$. Prompted this evidence our studies in the manuscript denoted that ruthenium-phloretin complex effectively, downregulates PI3K, Akt and mTOR in both MCF-7 and MDA-MB-231 cells.

Besides these, the growth factor of the epidermis and its receptors (EGFR) belongs to a transmembrane tyrosine kinase receptor which modulates cell proliferation and epithelial cell survival through PI3K / Akt / mTOR and (MAPK) pathways (64) and constantly over expressed in breast cancer (65), has been extensively explored in cancer chemotherapeutics $(66 ; 67 ; 68)$. Therefore, targeting the EGFR and VEGF signaling pathways is a recognized strategy for treating cancer (69). Our western blot results provide conclusive evidence that the complex acts on both EGFR and VEGF by down regulation their expressions in both MCF-7 and MDA-MB-231 cells.

Apoptotic stimulation has been considered to be a standard and best strategy in cancer therapeutics (70). In our current study, alteration of nuclear morphology was investigated by DAPI staining method using fluorescence microscopy and treatment with ruthenium phloretin complex clearly depicted the induction of apoptosis in these cells.

Newfound interest has lately been focused on the role of p53 in controlling cell growth (71) which triggered and regulates the target genes associated with cell cycle arrest, DNA repair, senescence and apoptosis (72). Reactivation of p53 in tumors has been reported to provoke tumor regression triggered by senescence induction (73). At molecular standpoint, DNA damage modulate P53 related signals which further leads to pro-apoptotic signals $(74 ; 75)$. Pro-apoptotic proteins including Bax damage the mitochondrial membranes and promote the secretion of cytochrome $\mathrm{c}$ and other pro-apoptotic factors, while anti-apoptotic proteins such as Bcl-2 and BclxL interfere with this action (76). Our western blot and immunohistochemical results indicated that there was an up-regulation of the activity p53, caspase- 3 and Bax, while down regulating the activity of Bcl-2 proteins, thus confirming our hypothesis that the novel complex acts via the p53 induced intrinsic apoptotic pathway regulated by Bax and Bcl-2.

Research revealed that a substantial increase in MMP-9 expression in cancerous tissues (77), occupies a crucial role in tumor invasion, metastasis and epithelial-to-mesenchymal transformation in breast cancer (78). Our studies denoted that ruthenium phloretin complex can effectively downregulate the MMP-9 expression and thus halt the breast cancer progression.

Recent studies indicated that redox balance and abrogate redox signaling are sturdily associated with malignancy and resistance to treatment (79). Thus, it can be expected that the up-regulation of SOD, GSH and CAT would result in the increment of $\mathrm{H}_{2} \mathrm{O}_{2}$ level in the mitochondria (80). Several studies have directed that mitochondrial $\mathrm{H}_{2} \mathrm{O}_{2}$ is a direct and effective apoptotic process inducer (81). Treatment of 
ruthenium-phloretin complex significantly elevated the expressions of SOD, CAT, and GSH in breast cancer, probably by stimulating the ROS to instigate the apoptotic events.

Unregulated proliferation is a hallmark feature of carcinoma and studies revealed that quantification of proliferation by immunohistochemical evaluation of Ki-67 antigen, often considered a prognostic factor for breast cancer and has been investigated in several studies $(82 ; 83 ; 84)$. Our study reveals that, the carcinogen control animals exhibited an upsurge in the number of cells labeled with Ki-67 and subsequently, a decrease of cells labeled with $\mathrm{Ki}-67$ and consequent increment of Al was observed post the treatment with ruthenium-phloretin complex.

In summary, ruthenium-phloretin complex is accountable for the p53 intervene apoptosis in the breast carcinoma, instigated by the intrinsic apoptotic trail facilitated by the Bcl2 and Bax and at the same time down regulating the PI3K/Akt/mTOR pathway coupled with MMP9 regulated tumor invasive pathways. Besides, the complex also exhibits antiangiogenic process by decrementing the EGFR and VEGF biomarkers. Moreover, the complex fruitfully demonstrated the intense activity on the free radical scavenging capabilities of breast carcinoma cells. The diminution of Ki-67coupled to the stimulation of p53 further heighten the fact that apoptosis was achieved by minimizing cellular proliferation. The outcomes give considerable proof (Fig. 7) that low dosages of ruthenium-phloretin chemotherapy could interrupt, revoke or suspend the succession of breast carcinoma by interacting with cancer biomarkers corelated with the initiation of apoptotic process thus altering intrinsic apoptosis along with the antiangiogenic pathway, hence fulfilling the role of a prospective candidate in cancer chemotherapeutics in the in the vicinity of future.

\section{Abbreviations}

DMSO (Dimethyl sulphoxide), TPTZ (2,4,6-Tri(2-pyridyl)-striazine), FT-IR (Fourier Transform Infrared Spectroscopic Analysis), XRD (X Ray Diffraction Spectroscopy), VEGF (vascular endothelial growth factor), FRAP (Ferric reducing antioxidant power), DPPH (1,1-diphenyl-2-picrylhydrazyl), ABTS (2, 2-azinobis(3-ethylbenzothiazoline-6-sulfonate)),NMR (Nuclear Magnetic Resonance), MTT (3-(4,5- dimethyl thiazole-2-yl)-2,5-diphenyltetrazolium bromide), mTOR (mammalian target of rapamycin), IR (Infrared Spectroscopy), DMBA (7,12-Dimethylbenz[a]anthracene), NCCS (National Centre for Cell Science), IICB (Indian Institute of Chemical Biology).

\section{Declarations}

\section{Author Contributions}

$\mathrm{CH}$ and JW conceived the study and participated in its design and co-ordination. SR and TC performed cell culture and cellular assays and carried out animal experiments. All authors read and approve the final manuscript. 


\section{Funding}

This work was funded by the National Natural Science Foundation of China (81560461) and was supported by medical high-level talent training plan and thousands of young and middle-aged backbone teachers cultivation plan of Guangxi province.

\section{Availability of data and materials}

All relevant data are within this published paper.

\section{Ethics approval and consent to participate}

The whole animal testing procedure was carried out in compliance with the endorsement of the Institutional Animal Ethics Committee \& the Government's Regulatory Body (Regd No. 1458/PO/a/11/CPCSEA).

\section{Consent for publication}

The publication was read and approved by all the authors participating in the study. The views, opinions, and findings contained in this report are those of the authors and do not reflect official policy of any institute or funding agency.

\section{Conflict of Interests}

All authors confirm that there is no conflict of interest.

\section{Author Details}

${ }^{1}$ Department of Oncology, The Second Affiliated Hospital of Xi'an Jiaotong University, Xi'an, 710004, China. ${ }^{2}$ Laboratory of Reproduction and Genetic, Affiliated hospital of Youjiang Medical College for Nationalities, Baise 533000, Guangxi, China. ${ }^{3}$ Department of Pharmacy, NSHM Knowledge CampusKolkata, 124 B.L. Saha Road, Kolkata 700053, West Bengal, India.

\section{References}

1. Bray F, Ferlay J, Soerjomataram I, et al. Global cancer statistics 2018: GLOBOCAN estimates of incidence and mortality worldwide for 36 cancers in 185 countries. CA Cancer J Clin. 2018;68:394- 
424.

2. Fan L, Goss PE, Strasser-Weippl K. Current Status and Future Projections of Breast Cancer in Asia. Breast Care (Basel). 2015;10:372-8.

3. Bruijnincx PCA, Sadler PJ. New trends for metal complexes with anticancer activity. Curr Opin Chem Biol. 2008;12:197-206.

4. Muhammad N, Guo Z. Metal-based anticancer chemotherapeutic agents. Curr Opin Chem Biol. 2014;19:144-53.

5. Oun R, Moussa YE, Wheate NJ. The side effects of platinum-based chemotherapy drugs: A review for chemists. Dalton Trans. 2018;47:6645-53.

6. Bergamo A, Sava G. Ruthenium anticancer compounds: Myths and realities of the emerging metalbased drugs. Dalton Trans. 2011;40:7817-23.

7. Trondl R, Heffeter P, Kowol CR, et al. NKP-1339, the first ruthenium-based anticancer drug on the edge to clinical application. Chem Sci. 2014;5:2925-32.

8. Alessio E. Thirty years of the drug candidate NAMI-A and the myths in the field of ruthenium anticancer compounds: A personal perspective. Eur J Inorg Chem. 2017; 2017: 1549-1560.

9. Vock CA, Ang WH, Scolaro C, et al. Development of ruthenium antitumor drugs that overcome multidrug resistance mechanisms. J Med Chem. 2007;50:2166-75.

10. Weiss $A$, Berndsen $\mathrm{RH}$, Dubois $\mathrm{M}$, et al. In vivo anti-tumor activity of the organometallic ruthenium(II)arene complex [Ru(n6 -p-cymene) $\mathrm{Cl}_{2}$ (pta)] (RAPTA-C) in human ovarian and colorectal carcinomas. Chem Sci. 2014;5:4742-8.

11. Alessio E, Messori L. NAMI-A and KP1019/1339, two iconic ruthenium anticancer drug candidates face-to-face: A case story in medicinal inorganic chemistry. Molecules. 2019;24:1995-2015.

12. Sudhakaran M, Sardesai S, Doseff Al. Flavonoids. New frontier for immuno-regulation and breast cancer control. Antioxidants (Basel). 2019;8:103-30.

13. Hou DX, Kumamoto T. Flavonoids as protein kinase inhibitors for cancer chemoprevention: Direct binding and molecular modeling. Antioxid Redox Signal. 2010;13:691-719.

14. Choi BY. Biochemical basis of anti-cancer-effects of phloretin-A natural dihydrochalcone. Molecules. 2019;24:278.

15. Tanaka K, Ono T, Umeda M. Inhibition of biological actions of 12-0-tetradecanoylphorbol-13-acetate by inhibitors of protein kinase C. Jpn J Cancer Res. 1986;77:1107-13.

16. Zhang Z, Li S, Cao H, Shen P, Liu J, Fu Y, Cao Y, Zhang N. The protective role of phloretin against dextran sulfate sodium-induced ulcerative colitis in mice. Food Funct. 2019;10:422-31.

17. Nam S, Lee SY, Ch HJ. Phloretin-loaded fast dissolving nanofibers for the locoregional therapy of oral squamous cell carcinoma. J Colloid Interface Sci. 2017;508:112-20.

18. Xu M, Gu W, Shen Z, Wang F. Anticancer activity of phloretin against human gastric cancer cell lines involves apoptosis, cell cycle arrest, and inhibition of cell invasion and JNK signalling pathway. Med Sci Monit. 2018;24:6551-8. 
19. Wu KH, Ho CT, Chen ZF, et al. The apple polyphenol phloretin inhibits breast cancer cell migration and proliferation via inhibition of signals by type 2 glucose transporter. J Food Drug Anal. 2018;26:22131.

20. Duan H, Wang R, Yan X, et al. Phloretin induces apoptosis of human esophageal cancer via a mitochondria-dependent pathway. Oncol Lett. 2017;14:6763-8.

21. Mariadoss AVA, Vinayagam R, Senthilkumar V, et al. Phloretin loaded chitosan nanoparticles augments the $\mathrm{pH}$-dependent mitochondrial-mediated intrinsic apoptosis in human oral cancer cells. Int J Biol Macromol. 2019;130:997-1008.

22. Parton M, Dowsett M, Smith I. Studies of apoptosis in breast cancer. B M J. 2001;322:1528-32.

23. Ray RS, Roy S, Ghosh S, Kumar M, Chatterjee M. Suppression of cell proliferation, DNA protein crosslinks, and induction of apoptosis by vanadium in chemical rat mammary carcinogenesis. Biochim Biophys Acta. 2004;1675:165-73.

24. Binder C, Marx D, Binder L, et al. Expression of bax in relation to bcl-2 and other predictive parameters in breast cancer. Ann Oncol. 1996;7:129-33.

25. Krajewski S, Thor AD, Edgerton SM, et al. Analysis of Bax and Bcl2 expression in p53 immunopositive breast cancer. Clin Cancer Res. 1997;3:199-208.

26. Ray RS, Ghosh B, Rana A, Chatterjee M. Suppression of cell proliferation, induction of apoptosis and cell cycle arrest: Chemopreventive activity of vanadium in vivo and in vitro. Int $\mathrm{J}$ Cancer. 2006;120:13-23.

27. Xing M, Deng X. Nicotine inactivation of the proapoptotic function of Bax through phosphorylation. $J$ Biol Chem. 2005;280:10781-9.

28. Bayramoglu A, Gunes HV, Metintas M, et al. The association of MMP-9 enzyme activity, MMP-9 C1562T polymorphism, and MMP-2 and - 9 and TIMP-1, -2, -3, and - 4 gene expression in lung cancer. Genet Test Mol Biomarkers. 2009;13:671-8.

29. Adams J, Carder PJ, Downey S, et al. Vascular endothelial growth factor (VEGF) in breast cancer: Comparison of plasma, serum, and tissue VEGF and microvessel density and effects of tamoxifen. Cancer Res. 2000;60:2898-905.

30. Zhou J, Wulfkuhle J, Zhang H, et al. Activation of the PTEN/mTOR/STAT3 pathway in breast cancer stem-like cells is required for viability and maintenance. Proc Natl Acad Sci USA. 2007;104:19655-6.

31. Anbuselvam C, Vijayavel K, Balasubramanian MP. Protective effect of Operculina turpethum against 7,12-dimethyl benz(a)anthracene induced oxidative stress with reference to breast cancer in experimental rats. Chem Biol Interact. 2007;168:229-36.

32. Norgan AP, Coffman PK, Kocher JPA, et al. Multilevel parallelization of AutoDock 4.2. J Cheminform. $2011 ; 3: 12$.

33. Seeliger D, Groot BLD. Ligand docking and binding site analysis with PyMOL and Autodock/Vina. J Comput Aided Mol Des. 2010;24:417-22. 
34. Zhang S, Kumar K, Jiang X, et al. DOVIS: an implementation for high-throughput virtual screening using AutoDock. BMC Bioinformatics. 2008;9:126-30.

35. Ezzati Nazhad Dolatabadi J, Mokhtarzadeh A, Ghareghoran SM, et al. Synthesis, Characterization and Antioxidant Property of Quercetin-Tb(III) Complex. Adv Pharm Bull. 2014;4(2):101-4.

36. Benzie IF, Strain JJ. The ferric reducing ability of plasma (FRAP) as a measure of "antioxidant power": the FRAP assay. Anal Biochem. 1996;239(1):70-6.

37. Pennycooke JC, Cox S, Stushnoff C. Relationship of cold acclimation, total phenolic content and antioxidant capacity with Chilling tolerance in petunia (Petunia hybrid). Environ Exper Bot. 2005;53:225-32.

38. Dehghan G, Dolatabadi JE, Jouyban A, et al. Spectroscopic studies on the interaction of quercetinterbium(III) complex with calf thymus DNA. DNA Cell Biol. 2011;30(3):195-201.

39. Li H, Wang Q, Dong L, et al. Morusin suppresses breast cancer cell growth in vitro and in vivo through C/EBPß and PPARY mediated lipoapoptosis. J Exp Clin Cancer Res. 2015;34:137.

40. Deng $X H$, Song $H Y$, Zhou $Y F$, et al. Effects of quercetin on the proliferation of breast cancer cells and expression of survivin in vitro. Exp Ther Med. 2013;6(5):1155-8.

41. Jagatheesh K, Arumugam V, Elangovan N, et al. Evaluation of the Anti-Tumor and Antioxidant Activity of Amorphophallus Paeonifolius on DMBA Induced Mammary Carcinoma. J chem pharm sci. 2010;1(2):40-50.

42. Sinha BB, Peterson GA, Li GC, et al. Nuclear change Distribution of isotone Pairs I. 31P and 32S. Phys. Rev C. 1972; (6):1657-1663.

43. Awasthi S, Kakkar P, Viswanathan PN, et al. Effect of anaesthetic ether on lipid peroxidation and superoxide dismutase isozymes of young and adult rat brain. Indian J Exp Biol. 1989;27(7):647-9.

44. Rotruck JT, Pope AL, Ganther HE, Swanson AB, Hafeman DG, Hoekstra WG. Selenium: biochemical role as a component of glutathione peroxidase. Science. 1973;179(4073):588-90.

45. Kessler ER, Su LJ, Gao D, et al. Phase II trial of acai juice product in biochemically recurrent prostate cancer. Integr Cancer Ther. 2018;17:1103-8.

46. Lesinski GB, Reville PK, Mace TA, et al. Consumption of soy isoflavone enriched bread in men with prostate cancer is associated with reduced proinflammatory cytokines and immunosuppressive cells. Cancer Prev Res. 2015;8:1036-44.

47. Pantuck AJ, Leppert JT, Zomorodian N, et al. Phase II study of pomegranate juice for men with rising prostate-specific antigen following surgery or radiation for prostate cancer. Clin Cancer Res. 2006;12:4018-26.

48. Kubatka P, Kello M, Kajo K, et al. Chemopreventive and therapeutic efficacy of cinnamomum zeylanicum L. bark in experimental breast carcinoma: Mechanistic in vivo and in vitro analyses. Molecules. 2020;25:1399.

49. Roy S, Ahmed F, Banerjee S, Saha U. Naringenin ameliorates streptozotocin-induced diabetic rat renal impairment by downregulation of TGF-b1 and IL-1 via modulation of oxidative stress correlates with 
decreased apoptotic events. Pharm Biol. 2016;54:1616-27.

50. Thota S, Rodrigues DA, Crans DC, Barreiro EJ. Ru(II) Compounds: Next-Generation Anticancer Metallotherapeutics? J Med Chem. 2018;61:5805-21.

51. Flocke LS, Trondl R, Jakupec M, et al. Molecular mode of action of NKP-1339 - A clinically investigated ruthenium-based drug - involves ER- and ROS-related effects in colon carcinoma cell lines. Invest New Drugs. 2016;34:261-8.

52. Merino D, Lok SW, Visvader JE, Lindeman GJ. Targeting BCL-2 to enhance vulnerability to therapy in estrogen receptor-positive breast cancer. Oncogene. 2016;35:1877-87.

53. Cang S, Iragavarapu C, Savooji J, et al. ABT-199 (venetoclax) and BCL-2 inhibitors in clinical development. J Hematol Oncol. 2015;8:129.

54. Pan R, Ruvolo VR, Wei J, et al. Inhibition of Mcl-1 with the pan-Bcl-2 family inhibitor (-)BI97D6 overcomes ABT-737 resistance in acute myeloid leukemia. Blood. 2015;126:363-72.

55. Zotano AG, Mayer IA, Arteaga CL. PI3K/AKT/mTOR: role in breast cancer progression, drug resistance, and treatment. Cancer Metastasis Rev vol. 2016;35:515-24.

56. Fruman DA, Chiu H, Hopkins BD, et al. The PI3K pathway inhuman disease. Cell. 2017;170:605-35.

57. Laplante MD, Sabatini M. mTOR signaling in growth control and disease. Cell. 2012;149:274-93.

58. Engelman JA. Targeting PI3K signalling in cancer: opportunities, challenges and limitations. Nat Rev Cancer. 2009;9:550-62.

59. Hanahan D, Weinberg RA. Hallmarks of cancer: The next generation. Cell. 2011;144:646-74.

60. Lien EC, Dibble CC, Toker A. PI3K signaling in cancer: Beyond AKT. Curr Opin Cell Biol. 2017. 62-71.

61. Martini M, Santis MCD, Braccini L, Gulluni F, Hirsch E. PI3K/AKT signaling pathway and cancer: an updated review. Ann Med. 2014;46:372-83.

62. Fruman DA, Rommel C. PI3K and cancer: Lessons, challenges and opportunities. Nat Rev Drug Discov. 2014;13:140-56.

63. Davis NM, Sokolosky M, Stadelman K, et al. Deregulation of the EGFR/ PI3K/ PTEN/ Akt/ mTORC1 pathway in breast cancer: Possibilities for therapeutic intervention. Oncotarget. 2014;5:4603-50.

64. Mitsudomi T, Yatabe Y. Epidermal growth factor receptor in relation to tumor development: EGFR gene and cancer. FEBS J. 2010;277:301-8.

65. Huang L, Wong CC, Mackenzie GG, et al. Phospho-aspirin (MDC-22) inhibits breast cancer in preclinical animal models: An effect mediated by EGFR inhibition, p53 acetylation and oxidative stress. BMC Cancer. 2014;28:14-141.

66. Schladt TD, Schneider K, Schild H, Tremel W. Synthesis and bio-functionalization of magnetic nanoparticles for medical diagnosis and treatment. Dalton Trans. 2011;40:6315-43.

67. Ding Y, Liu J, Wang H, Shen G, Yu R. A piezoelectric immunosensor for the detection of alphafetoprotein using an interface of gold / hydroxyapatite hybrid nanomaterial. Biomaterials. 2007;28:2147-2154. 
68. Sperling RA, Rivera P, Gil P, Zhang F, Zanella M, Parak WJ. Biological applications of gold nanoparticles. Chem Soc Rev. 2008;37:1896-981.

69. Kumar BNP, Puvvada N, Rajput S, et al. Targeting of EGFR, VEGFR2, and Akt by engineered dual drug encapsulated mesoporous silica-gold nanoclusters sensitizes tamoxifen-resistant breast cancer. Mol Pharm. 2018;15:2698-713.

70. Hassan M, Watari H, AbuAlmaaty A, et al. Apoptosis and molecular targeting therapy in cancer. Biomed Res Int. 2014; 2014:150845.

71. Kastenhuber ER, Lowe SW. Putting p53 in Context. Cell. 2017;170:1062-78.

72. Fischer M. Census and evaluation of p53 target genes. Oncogene. 2017;36:3943-56.

73. Ventura A, Kirsch DG, McLaughlin ME, et al. Restoration of p53 function leads to tumour regression in vivo. Nature. 2007;445:661-5.

74. Miyashita T, Reed JC. Tumor-Suppressor P53 is a direct transcriptional activator of the human bax gene. Cell. 1995;80:293-9.

75. Jiang P, Du WJ, Heese K, Wu M. The bad guy cooperates with good cop p53: Bad is transcriptionally up-regulated by p53 and forms a bad/p53 complex at the mitochondria to induce apoptosis. Mol Cell Biol. 2006;26:9071-82.

76. Nam GH, Jo KJ, Park YS, et al. In vitro and in vivo Induction of p53-dependent apoptosis by extract of euryale ferox salisb in A549 human caucasian lung carcinoma cancer cells is mediated through Akt signaling pathway. Front Oncol. 2019;9:406.

77. Cao D, Polyak K, Halushka MK, et al. Serial analysis of gene expression of lobular carcinoma in situ identifies downregulation of claudin 4 and overexpression of matrix metalloproteinase 9 . Breast Cancer Res. 2008;10:R91.

78. Balduyck M, Zerimech F, Gouyer V, et al. Specific expression of matrix metalloproteinases 1, 3, 9 and 13 associated with invasiveness of breast cancer cells in vitro. Clin Exp Metastasis. 2000;18:171-8.

79. Panieri E, Santoro MM. ROS homeostasis and metabolism: A dangerous liason in cancer cells. Cell Death Dis. 2016;7:e2253.

80. Giorgio M, Trinei M, Migliaccio E,. Pelicci PG. Hydrogen peroxide: a metabolic byproduct or a common mediator of ageing signals? Nat Rev Mol Cell Biol. 2007;8:722-8.

81. Khan Md A, Chen HC, Wan X. et.al. Regulatory effects of resveratrol on antioxidant enzymes: A mechanism of growth inhibition and apoptosis induction in cancer cells". Mol Cells. 2013;35:21925.

82. Dowsett M, Nielsen TO, A'Hern R, et al. Assessment of Ki67 in breast cancer: Recommendation from the international Ki67 in breast cancer working group. J Natl Cancer Inst. 2011;103:1656-64.

83. Yerushalmi R, Woods R, Ravdin PM, et al. Ki67 in breast cancer: prognostic and predictive potential. Lancet Oncol. 2010;11:174-83.

84. Azambuja ED, Cardoso F, Castro GD Jr, et al. Ki-67 as prognostic marker in early breast cancer: A meta-analysis of published studies involving 12,155 patients. Br J Cancer. 2007;96:1504-13. 
Figures
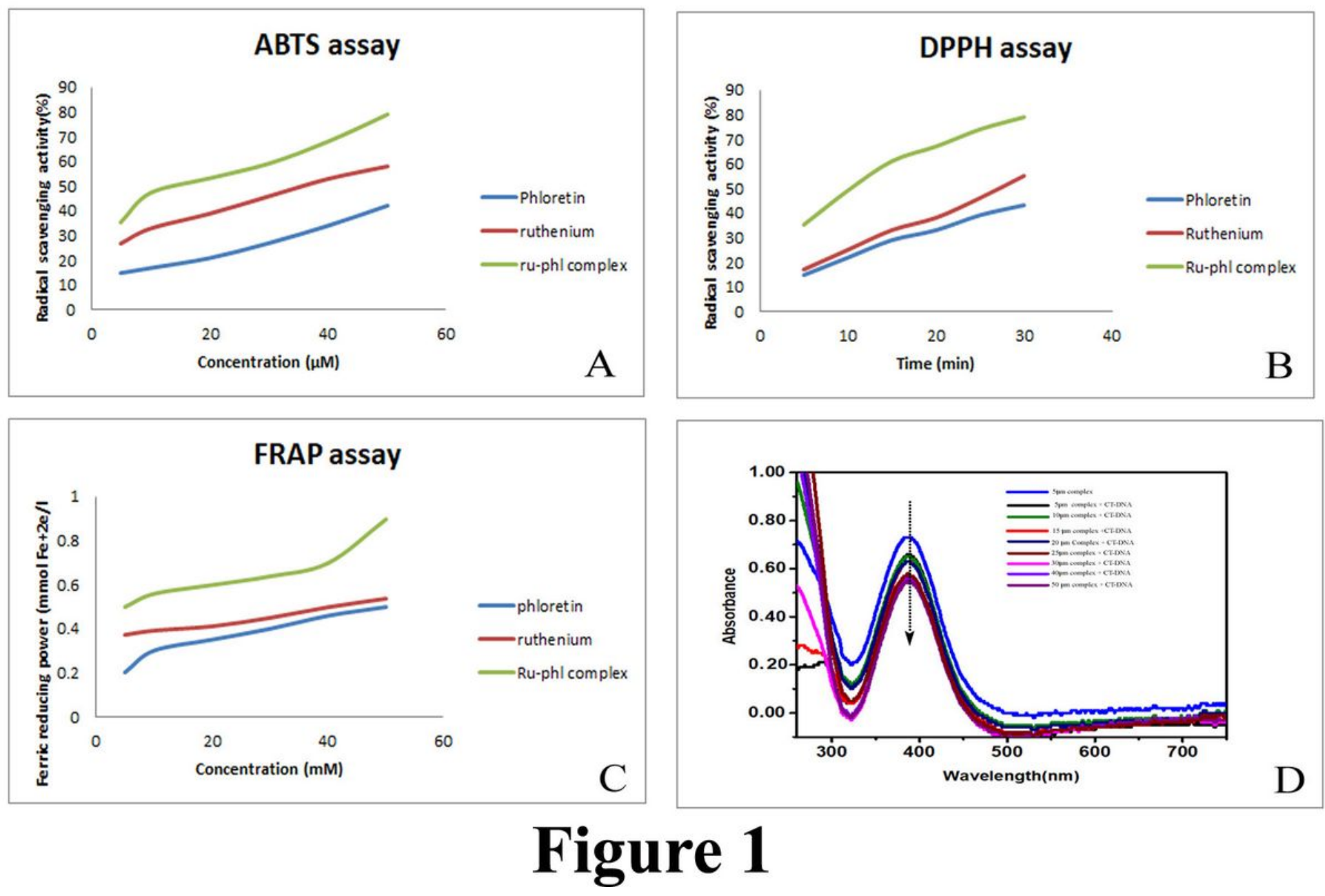

Figure 1

Measurement of anti-oxidant activity of the complex. [A] Anti-oxidant activity of ruthenium-phloretin complex by ABTS method [B] DPPH method [C] FRAP method [D] Absorbance spectra of CT-DNA in the presence of ruthenium-phloretin complex. 

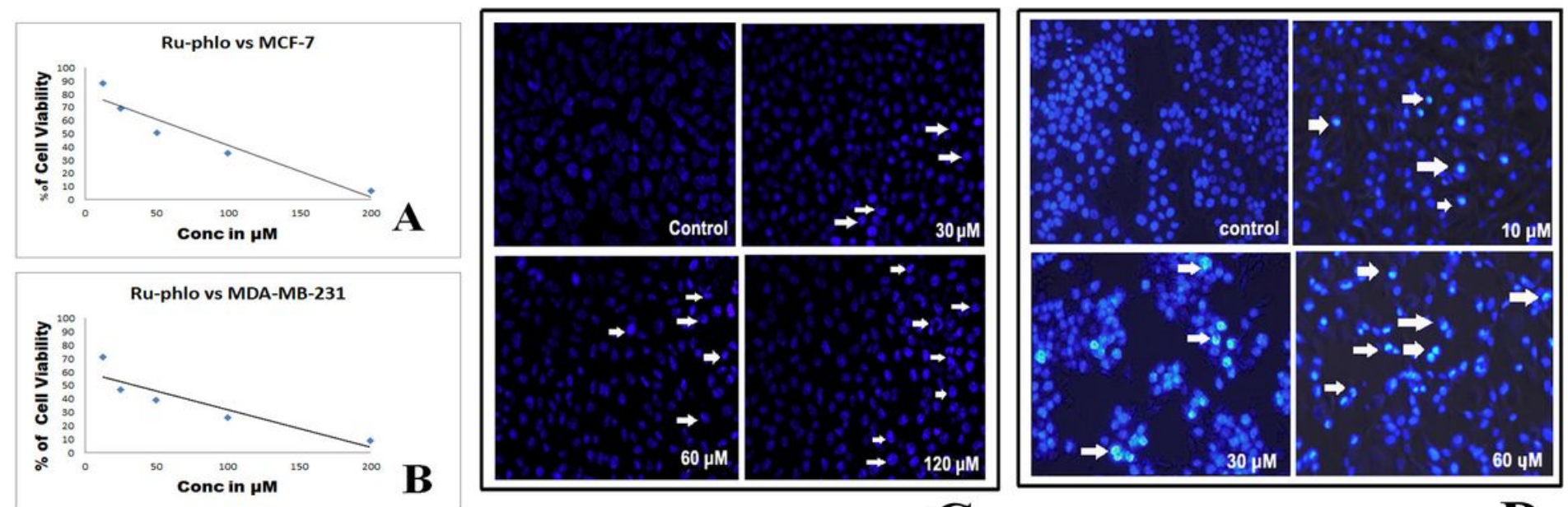

B

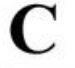

D
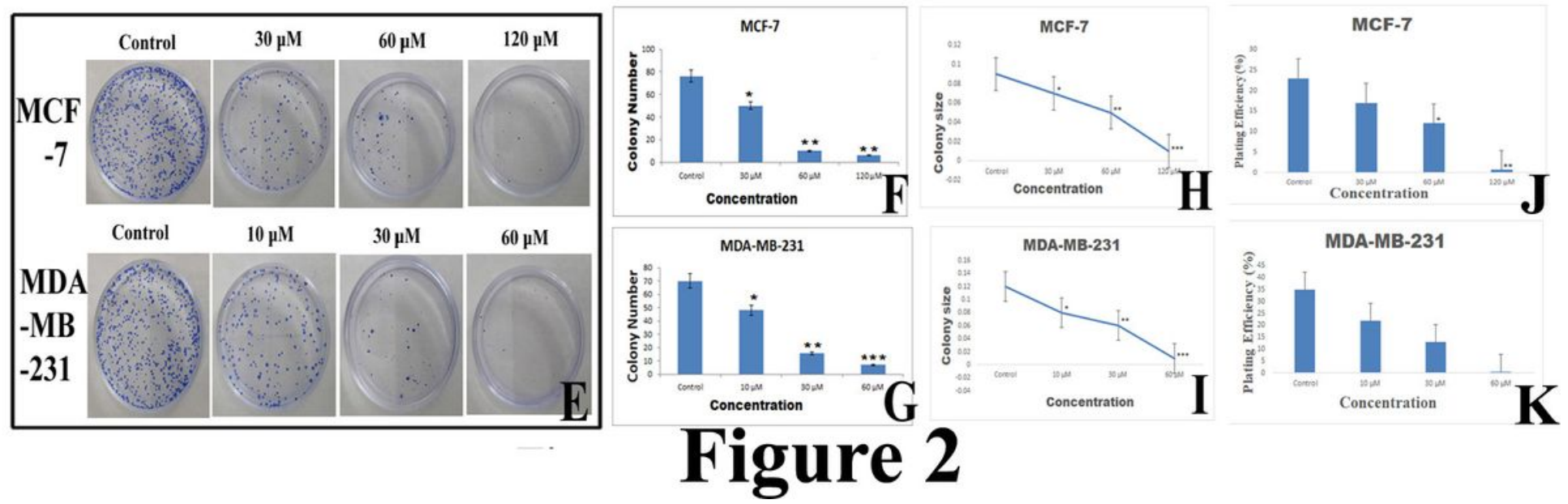

\section{Figure 2}

Effects of ruthenium-phloretin complex on cell viability of [A] MCF-7 cells and [B] MDA-MB-231 cells at 24 hours. [C] DAPI stained MCF-7 cells after 24 hours of treatment with ruthenium-phloretin complex [D] DAPI stained MDA-MB-231 cells after 24 hours of treatment with ruthenium-phloretin complex [E] Clonogenic assay of MCF-7 and MDA-MB-231 cells after 24 hours of treatment with ruthenium-phloretin complex [F] Quantification of colony number for MCF-7 cells. [G] Quantification of colony number for MDA-MB-231 cells [H] Quantification of colony size for MCF-7 cells [I] Quantification of colony size for MDA-MB-231 cells [J] Plate efficiency for Clonogenic assay of MCF-7 cells [K] Plate efficiency for Clonogenic assay of MDA-MB-231 cells. Quantification of colony number and size was performed using Image $\mathrm{J}$ public domain software. Data represent means \pm SD from three different experiments in triplicate. The results were compared using ANOVA, followed by a Tukey's post-hoc analysis. Asterisks represent ${ }^{*} p \leq 0.05,{ }^{*} p \leq 0.01, * \star * p \leq 0.001$ compared to control. 

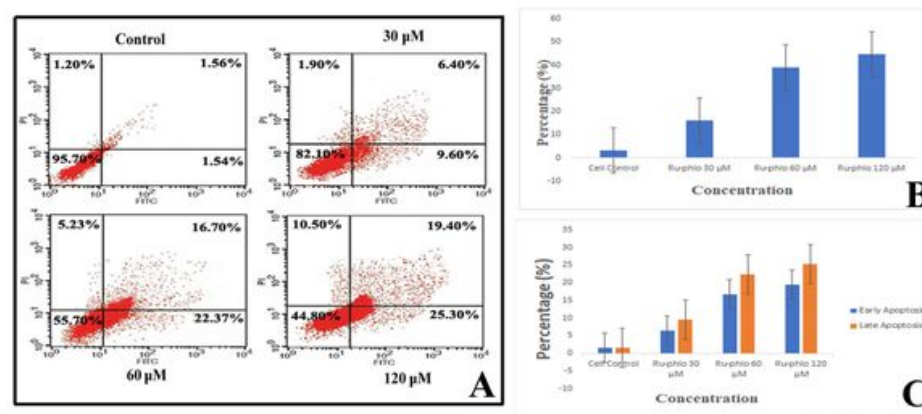

C
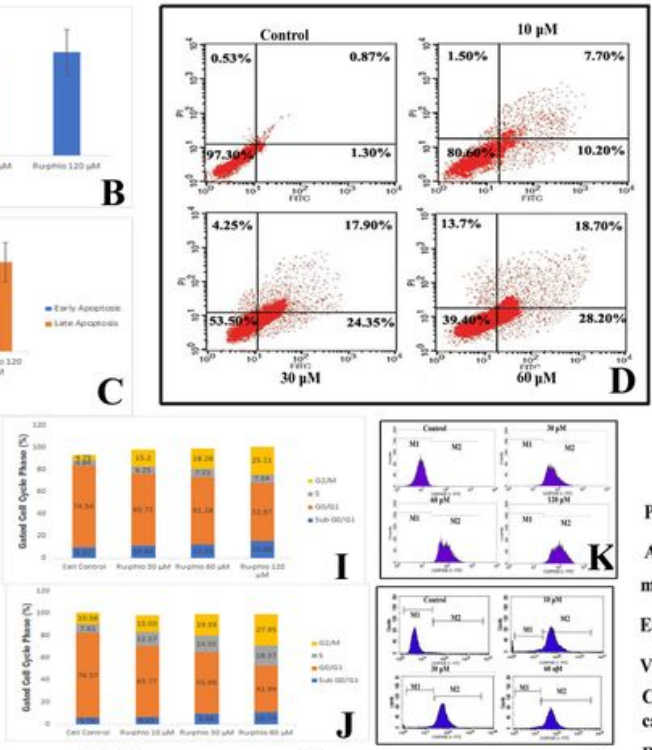

Figure 3

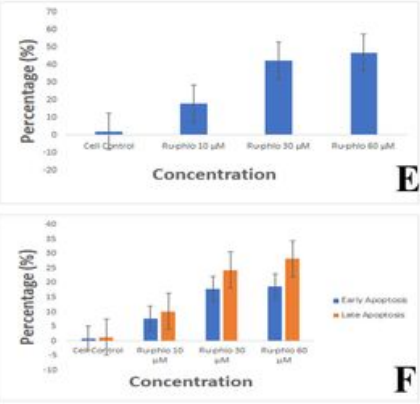

MCF-7 MDA-MB-231

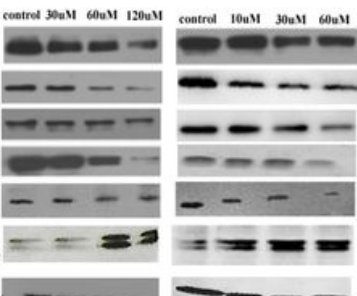

M

Figure 3

[A] Detection of apoptosis in MCF-7 cells by Flow cytometry after treatment with ruthenium-phloretin complex. [B] Percentage of apoptotic cells versus concentration in MCF-7 cells [C] Percentage of apoptotic cells in early and late apoptosis stage in MCF-7 cells [D] Detection of apoptosis in MDA-MB-231 cells by Flow cytometry after treatment with ruthenium-phloretin complex. [E] Percentage of apoptotic cells versus concentration in MDA-MB-231 cells [F] Percentage of apoptotic cells in early and late apoptosis stage in MDA-MB-231 cells [G] Analysis of cell cycle phase distribution of MCF-7 cells after the treatment with ruthenium-phloretin complex [H] Analysis of cell cycle phase distribution of MDA-MB231cells after the treatment with ruthenium-phloretin complex [1] Quantitative of distribution of MCF-7 cells in different phases of cell cycle [J] Quantitative of distribution of MDA-MB-231cells in different phases of cell cycle [K] Expression of caspase-3 proteins in MCF-7 cells after 24 hours of treatment with ruthenium-phloretin complex [L] Expression of caspase-3 proteins in MDA-MB-231cells after 24 hours of treatment with ruthenium-phloretin complex [M] Western blot analysis of expressions of PI3K, Akt, mTOR, EGFR, VEGF and cleaved caspase-3 in MCF-7 and MDA-MB-231 cells. 

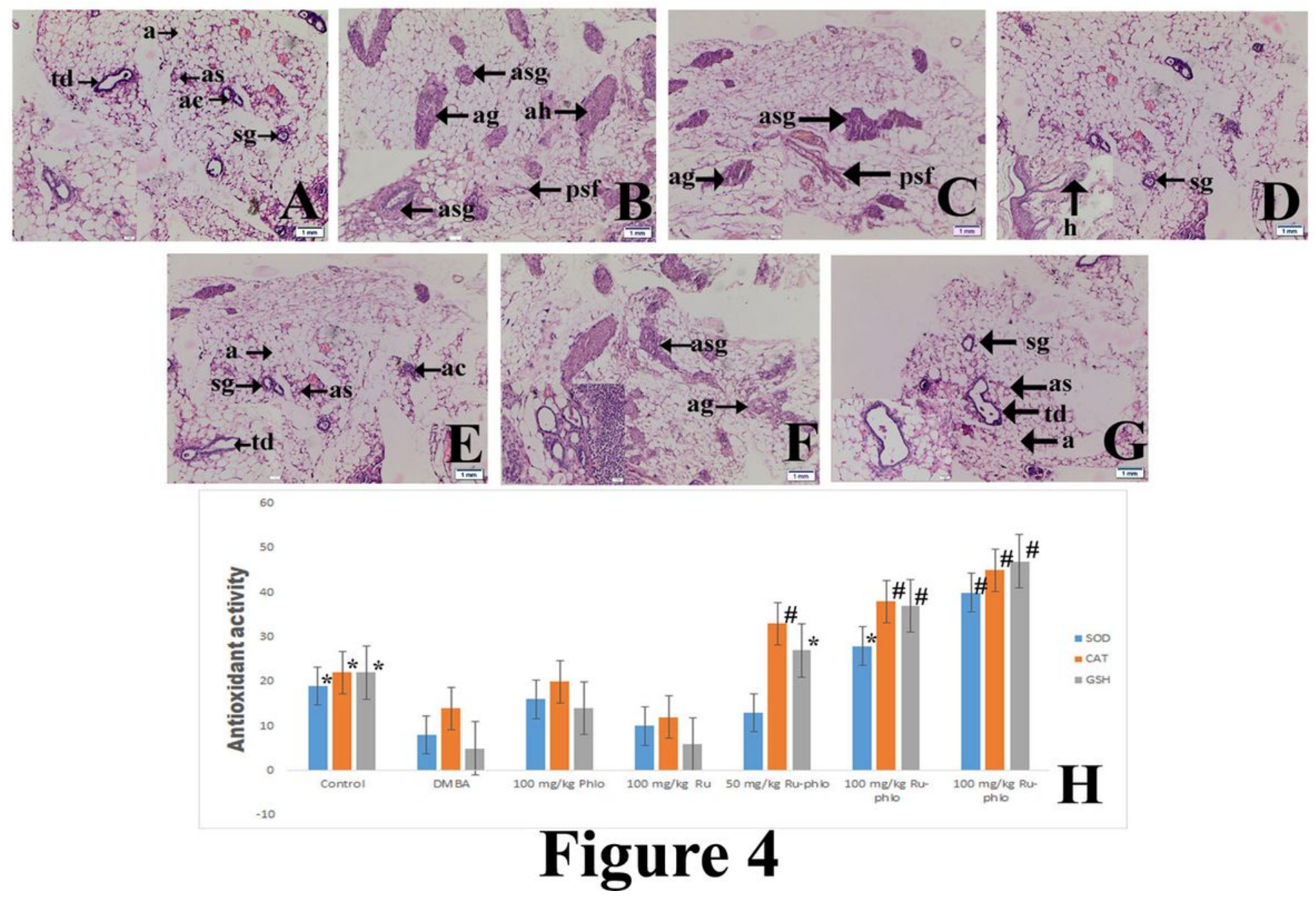

\section{Figure 4}

[A] Histological appearance of mammary tissue of normal control showing Terminal duct lobular units (td), alveoli (a), alveolar septa (sg), Acinus(ac), serous gland (sg) [B] DMBA control shows atrophy of glands with periductal stromal fibrosis and fatty tissue (psf), atrophy of glands (ag) with surrounding fatty tissue, atrophy of serous glands (asg) with surrounding stromal fibrosis, Atypical hyperplasia (ah). [C] Mammary tissue of DMBA induced group treated with $50 \mathrm{mg} / \mathrm{kg}$ ruthenium-phloretin complex showing atrophy of serous glands (asg), atrophy of glands (ag) and periductal stromal fibrosis and fatty tissue (psf) [D] Mammary tissue of DMBA induced group treated with $100 \mathrm{mg} / \mathrm{kg}$ ruthenium-phloretin complex showing hyperplasia of serous and mucinous glands (h) [E] Mammary tissue of DMBA induced group treated with $100 \mathrm{mg} / \mathrm{kg}$ ruthenium-phloretin complex having almost normal architecture [F] Mammary tissue of DMBA induced group treated with $100 \mathrm{mg} / \mathrm{kg}$ ruthenium [G] Mammary tissue of DMBA induced group treated with $100 \mathrm{mg} / \mathrm{kg}$ phloretin. [H] Effect of ruthenium- phloretin complex on invivo antioxidant enzymes SOD (superoxide dismutase) and CAT (catalase), (glutathione) GST. * $p<0.05$ as compared to the carcinogen control, \# $\mathrm{p}<0.01$ as compared to the ruthenium, phloretin, Rutheniumphloretin 50, 100 and $200 \mathrm{mg} / \mathrm{kg}$. 

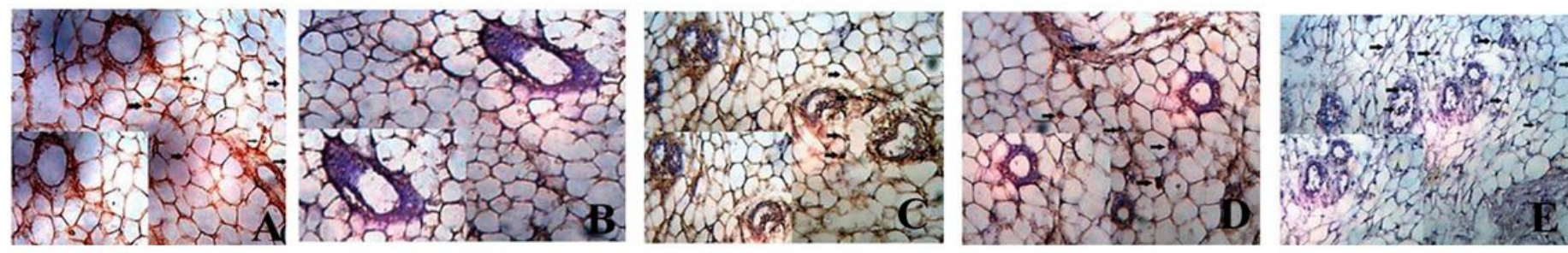

(i)
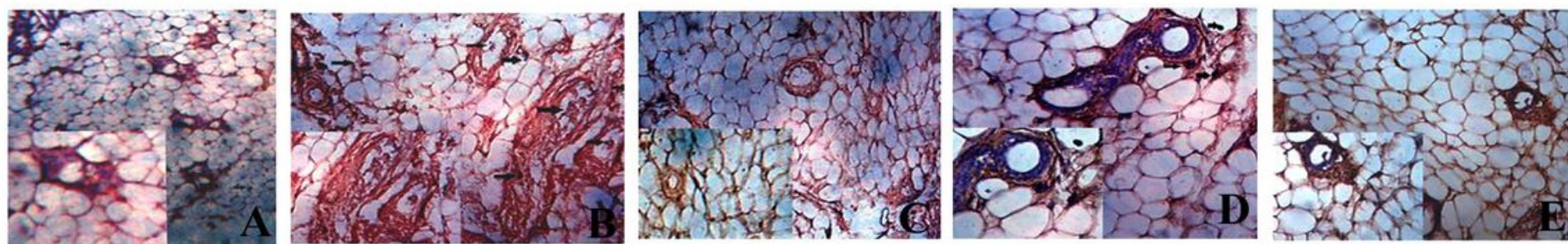

(ii)
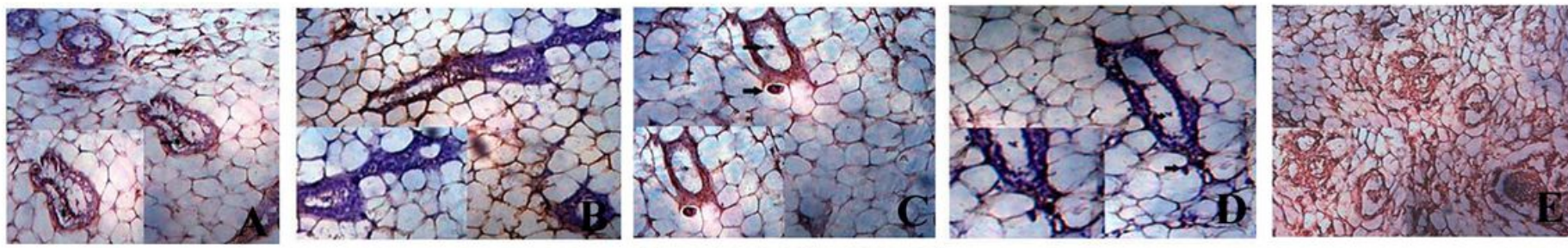

(iii)
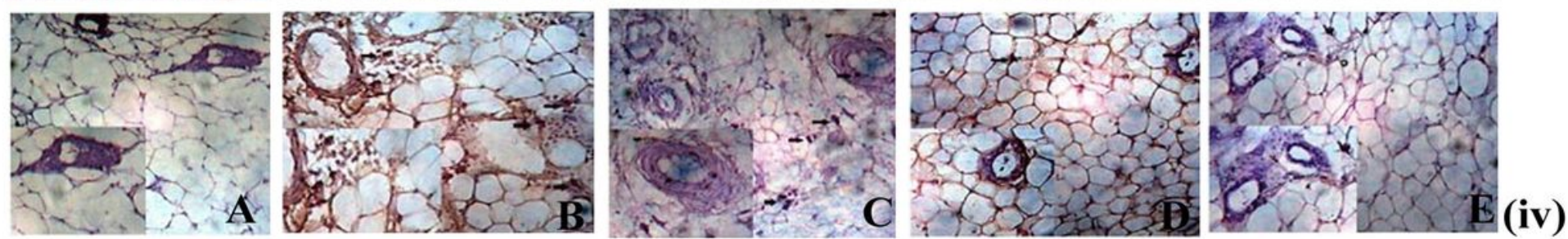

Figure 5

\section{Figure 5}

The immunohistochemical analysis of the (i)p53, (ii)Bcl2, (iii) Bax and (vi) MMP9 expressions in the colon tissues of different groups of rats (A) the normal control (B) carcinogen control (C) $50 \mathrm{mg} / \mathrm{kg}$ of complex treated (D) \& (E) 100 and $200 \mathrm{mg} / \mathrm{kg}$ complex treated. All images at 40X.
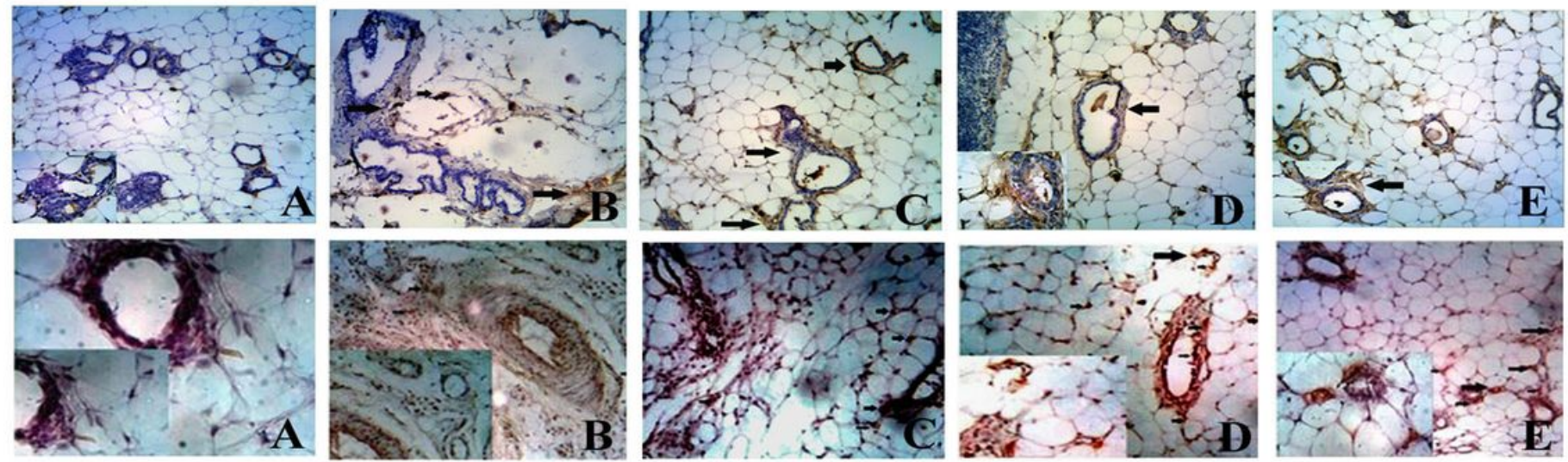

Figure 6

(ii)

Figure 6 
The immunohistochemical analysis of expression of Ki-67 of different group of rats $(A)$ the normal control (B) carcinogen control (C) $50 \mathrm{mg} / \mathrm{kg}$ of complex treated (D) \& (E) 100 and $200 \mathrm{mg} / \mathrm{kg}$ complex treated. All images at 40X. (ii) TUNEL assay of apoptotic (A) the normal control (B) carcinogen control (C) $50 \mathrm{mg} / \mathrm{kg}$ of complex treated (D) \& (E) 100 and $300 \mathrm{mg} / \mathrm{kg}$ complex treated. All images at 40X.



Figure 7

The molecular mechanistic pathway of Ruthenium-phloretin complex in mammary cancer.

\section{Supplementary Files}

This is a list of supplementary files associated with this preprint. Click to download.

- graphicalAbstract.jpg

- Supplementarytables.docx

- Supplementarymanuscript.docx

- SupplementaryFigurelegends.docx 
- SupplementaryFigure2.jpg

- SupplementaryFigure1.jpg 